\title{
O ENSINO DE GEOGRAFIA EM CURSOS DE PEDAGOGIA À DISTÂNCIA
}

\author{
Sarah Mendonça Araújo \\ Universidade Federal de Uberlândia, Uberlândia, Minas Gerais, Brasil \\ Iara Vieira Guimarães \\ Universidade Federal de Uberlândia, Uberlândia, Minas Gerais, Brasil
}

\begin{abstract}
Resumo: Este artigo apresenta uma análise acerca das propostas curriculares das disciplinas voltadas para o ensino de Geografia nos projetos pedagógicos dos cursos de Pedagogia, na modalidade à distância, de instituições públicas de Ensino Superior das regiões Centro-Oeste, Sul e Sudeste do País, buscando identificar os delineamentos desta área de ensino nos referidos cursos. O texto aborda perspectivas teórico-metodológicas do ensino de Geografia e apresenta os resultados. Considera-se que o delineamento curricular da disciplina Geografia, no processo de formação dos professores na modalidade à distância, está longe de expressar consenso ou uma perspectiva similar nas universidades investigadas.

Palavras-chave: Ensino de Geografia. Educação à distância. Pedagogia.
\end{abstract}

\section{DEFININDO O PERCURSO}

O ensino de Geografia, em sua trajetória histórica, vem a constituir-se numa área de muitas inquietações e transformações. Por anos, o ensino dessa disciplina foi marcado por metodologias de ensino baseadas na memorização, no ensino enciclopedista e por uma abordagem que pouco questionava a realidade. Essas características se fizeram presentes, principalmente, nos anos iniciais do ensino fundamental, cujos professores são formados em cursos de Pedagogia, apresentando, em sua maioria, uma formação genérica 
e superficial em relação às disciplinas específicas. Assim, vislumbramos o interesse em investigar como as propostas curriculares dessa disciplina vêm sendo delineadas nos projetos pedagógicos dos cursos de Pedagogia na modalidade à distância de instituições públicas de Ensino Superior. É importante ressaltar que a educação à distância configura-se, prioritariamente, como sendo uma modalidade voltada para a formação de professores, uma vez que essa modalidade vem recebendo incentivos significativos do Governo Federal, com o objetivo de elevar o grau de titularidade dos professores da educação básica e, por conseguinte, a qualidade desta.

Nosso corpus de estudo constituiu-se de vinte e um projetos pedagógicos dos cursos de Pedagogia na modalidade à distância, ofertados nas Instituições Públicas de Ensino Superior - IPES das regiões CentroOeste, Sul e Sudeste do País, tendo utilizado-se como metodologia a análise documental. A escolha pela análise do projeto pedagógico dos cursos ocorreu por considerarmos que esse documento expressa os princípios de como se dará, ou, pelo menos, de como foi pensada, a prática pedagógica para os cursos. De acordo com Vasconcelos (2008), um projeto de curso requer um trabalho reflexivo e investigativo de toda a equipe envolvida e, por isso, não deve ser algo imposto. Caso seja elaborado de forma participativa, consciente e reflexiva, ele poderá ser um facilitador do desenvolvimento e da organização do curso, e possibilitará atingir a qualidade do trabalho desenvolvido.

Entretanto, cabe ressaltar que no fazer pedagógico, muitas vezes, as atitudes tomadas são baseadas em soluções urgentes, sem uma reflexão sobre as situações que ocorrem no ambiente educativo. O Projeto pode ser considerado uma forma de tentar resolver esses problemas por meio de planejamentos e reflexões anteriores, num processo de revisão e replanejamento contínuos. Vasconcellos (2008, p. 169) reconhece o Projeto Político Pedagógico como"[um] instrumento teórico metodológico para a intervenção e mudança da realidade".

A coleta dos projetos pedagógicos junto às instituições foi realizada por meio de solicitações encaminhadas via correio eletrônico e pesquisa na internet. Para termos acesso aos projetos não disponibilizados pelas instituições, realizamos uma busca nos sites das instituições de ensino superior e também nas páginas do Governo Federal, em especial do Sistema Universidade Aberta do Brasil - SisUAB.

Tendo em vista a grande quantidade de cursos que se enquadravam no nosso perfil de interesse, selecionamos os cursos das regiões Centro-oeste, Sul e Sudeste do País, oferecidos no âmbito do Sistema Universidade Aberta do Brasil - UAB. 
O gráfico abaixo demonstra o destaque do curso de Pedagogia à distância, no contexto da educação superior à distância no Brasil:

Gráfico 1 - Dez maiores cursos de graduação à distância em número de matrículas

\begin{tabular}{|c|c|}
\hline Nome do curso & Número de Alunos \\
\hline Pedagogia & 273248 \\
\hline Administração & 128186 \\
\hline Serviço Social & 74474 \\
\hline Competências Gerais & 45880 \\
\hline Ciências Contábeis & 40936 \\
\hline Gestão de Pessoal / Recursos Humanos & 35486 \\
\hline Administração Pública & 34611 \\
\hline Formação de Professor de Português & 28591 \\
\hline Formação de Professor de Matemática & 23328 \\
\hline Formação de Professor de Biologia & 087 \\
\hline
\end{tabular}

Fonte: Censo da Educação Superior, 2010/INEP

Conforme explicitado no gráfico acima, os números demonstram que o curso de Pedagogia tem destaque no âmbito nacional em função do considerável número de ofertas na modalidade à distância, principalmente depois da implantação do sistema UAB. Esses cursos, sem dúvida, estão sendo base para a formação de muitos docentes que atuam na educação básica, estes os quais são os responsáveis pela formação de um número significativo de crianças e jovens. Assim, esse público escolar está obtendo a base para o desenvolvimento de vários conhecimentos, dentre eles os conhecimentos geográficos, com muitos professores que são provenientes dos cursos de Pedagogia à distância, tornando-se ainda mais importante conhecer como o ensino de Geografia vem sendo proposto nestes cursos à distância, nos quais estão matriculados mais de 200.000 alunos, e possíveis futuros docentes que atuarão nos anos iniciais. 
O ensino de GeOgRAFIA E AS TENDÊNCIAS ATUAIS PARA O SEU DESENVOLVIMENTO

Diante da realidade em que vivemos, marcada pela globalizalização e seus impactos sociais, a Geografia configura-se como um campo importante da educação, porque possibilita a leitura crítica do espaço. Salientamos que o espaço geográfico é fruto das relações histórico-sociais estabelecidas entre homem e sociedade. De acordo com Cavalcanti (2010, p. 4) no processo de globalização:

observa-se maior interdependência entre as escalas nas quais os fenômenos e fatos espaciais ocorrem, maior e mais intensa comunicação entre as pessoas, empresas e instituições, levando à experiência simultânea (mas não homogênea) com esses fenômenos e fatos, ao adensamento de pessoas em territórios urbanos e globais e globalizados, a padronização de estilos de vida, mas também à acentuação da diversidade cultural.

O Ensino de Geografia passou por mudanças significativas nas últimas décadas do século XX, ocorridas tanto no modo de pensar a disciplina como na forma de ensiná-la. Assim, torna-se importante enfatizar os avanços e retrocessos ocorridos no decorrer da história da Geografia escolar no Brasil, destacando as mudanças e permanências e as perspectivas que podem ser vislumbradas para o futuro. Observamos que durante muitos anos o ensino de Geografia foi desenvolvido de forma enciclopédica e pouco questionadora, baseado em uma mera descrição do espaço. Callai (2005) considera os conhecimentos geográficos como fortes aliados para que os alunos possam realizar a leitura de mundo, desenvolver a cidadania e ser um agente ativo de transformação em sua realidade.

Ler o mundo da vida, ler o espaço e compreender que as paisagens que podemos ver são resultado da vida em sociedade, dos homens na busca da sua sobrevivência e da satisfação das suas necessidades. Em linhas gerais, esse é o papel da geografia na escola. Refletir sobre as possibilidades que representa, no processo de alfabetização, o ensino de geografia, passa a ser importante para quem quer pensar, entender e propor a geografia como um componente curricular significativo. (CALLAl, 2005, p. 228)

Assim, podemos considerar que para a Geografia fazer parte do currículo da escola básica, há que se levar em conta a amplitude dos conhecimentos geográficos como possibilidade de se entender, de forma questionadora e analítica, o mundo em que vivemos, e agir sobre ele. Conforme assinala Cavalcante (2002), 
o objeto de estudo geográfico na escola é, pois, o espaço geográfico, entendido como um espaço social, concreto, em movimento. Um estudo do espaço assim concebido requer uma análise da sociedade e da natureza, e da dinâmica resultante da relação entre ambas (CAVALCANTI, 2002, p. 13).

O espaço geográfico deve ser entendido como um espaço transformado pelos seres humanos. Para apreendê-lo é necessária a superação da abordagem descritiva e a abertura para o desenvolvimento do raciocínio espacial mais complexo. Para isso, ressaltamos a importância da compreensão, por meio das referências teórico-conceituais, das decorrências e determinações das localizações. Segundo Cavalcanti (2002), a localização é uma perspectiva particular dessa disciplina. Podemos considerar que mais do que uma descrição física de um lugar, é importante analisarmos outros aspectos ligados à organização social, à cultura, às relações de poder, ao modo como os grupos sociais se relacionam com a natureza e ao uso que se faz dela.

Nessa perspectiva, trabalhar os conceitos geográficos ganha relevância para se construir o chamado raciocínio espacial. De acordo com Cavalcanti (2002), na linha da didática histórico-crítica, os conceitos devem ser construídos por meio do confronto entre conceitos científicos e cotidianos, o que demanda considerar os conhecimentos prévios dos alunos, a fim de torná-los sujeitos do processo de ensino e aprendizagem. As habilidades que carecem de atenção ao se trabalhar com o espaço geográfico, como observação, mapeamento, orientação, localização, representação cartográfica e a prática de leitura de diversas fontes e registros, devem perpassar os diversos conteúdos da Geografia escolar.

Constatamos que não somente no ensino de Geografia, mas também na educação como um todo, as práticas tradicionais ainda se fazem presentes. Trata-se muitas vezes, de ações pedagógicas fragmentadas e descontextualizadas da realidade dos alunos. No caso específico da Geografia nos anos iniciais, podemos destacar as práticas que ainda tratam de maneira linear as escalas geográficas. Segundo Callai (2005), o ensino de Geografia, partindo da chamada "hierarquização fragmentada" (do mais próximo para o mais distante), desconsidera a complexidade do mundo em que vivemos. Para a autora o mais importante não é criticar a ordem com que se trabalham os níveis de hierarquização (casa, escola, cidade, estado, país...), mas a forma isolada de se trabalhar cada nível ou escala geográfica.

Guimarães et al. (2012, p. 339) argumentam que essa abordagem, denominada "círculos concêntricos", serviu muitos anos para a organização do ensino de Geografia nas escolas. No entanto, tal abordagem já não se apresenta 
suficiente para explicar as relações existentes no mundo globalizado, já que seu objetivo era apenas respeitar o grau de maturidade das crianças, mas acabava por seguir "um percurso linear e fragmentado ao tratar das escalas geográficas". Importante ressaltar que tal crítica é realizada desde a década de 1990 e, lamentavelmente, ainda não se pode confirmar que tal abordagem foi superada na escola (CAVALCANTI, 2010).

Callai (2005, p. 231) considera que "a clareza teórico-metodológica é fundamental para que o professor possa contextualizar os seus saberes, os dos seus alunos, e os de todo mundo à sua volta". Consideramos que o momento adequado para se refletir e para se buscar a melhor alternativa teóricometodológica, que trata com a clareza necessária das concepções de educação e de Geografia, é quando se pensa na disciplina e, para além disso, quando se pensa no Projeto Pedagógico. É nesse documento que se espera a clareza necessária a respeito da abordagem teórico-metodológica que será trabalhada e que sejam traçados os caminhos para se chegar aos objetivos propostos.

Nesse sentido, a interdisciplinaridade é apontada por Callai (2005) como um caminho profícuo para a prática educativa nos anos iniciais da educação básica, principalmente no processo de alfabetização, porque possibilita a aprendizagem da leitura e da escrita em consonância com a leitura de mundo, considerando o contexto histórico e geográfico do aluno. A esse respeito, Pontuschka et al. (2009, p. 145) salientam que:

A interdisciplinaridade pode criar novos saberes e favorecer uma aproximação maior com a realidade social mediante leituras diversificadas do espaço geográfico e de temas de grande interesse e necessidade para o Brasil e para o mundo. O professor de uma disciplina específica com uma atitude interdisciplinar abre a possibilidade de ser um professor-pesquisador porque deve selecionar os conteúdos, métodos e técnicas trabalhados em sua disciplina e disponibilizá-lo para contribuir com um objeto de estudo em interação com os professores das demais disciplinas. Isso não pode ser realizado sem uma pesquisa permanente.

Conforme afirmam Pontuschka et al. (op. cit.) a atitude interdisciplinar requer do professor uma postura de pesquisador que busca a relação dialógica de sua disciplina com outras áreas do conhecimento. Essa atitude possibilita ao professor um olhar mais apurado sobre as questões atuais e complexas da realidade, e até mesmo o aprofundamento sobre sua própria disciplina. Tal postura se faz necessária para que o professor seja capaz de realizar uma leitura de mundo que possibilite aos seus alunos o desenvolvimento do olhar crítico. 
De acordo com Callai (2005, p. 237), para que essa leitura de mundo seja possível torna-se indispensável desenvolver o que a autora denomina de "olhar espacial". Para a autora a especificidade da análise geográfica consiste em, "por meio do olhar espacial, compreender o mundo da vida, entender as dinâmicas sociais, como se dão as relações entre os homens e quais as limitações/condições/possibilidades econômicas e políticas que interferem" em seu quotidiano. Em função disso, a história de um determinado espaço pode ser desvendada por meio da leitura da paisagem, pela reflexão sobre o lugar de vivência. Ambos estão imbuídos de historicidade, ou seja, o que é mostrado na paisagem e o que é vivido no lugar, é resultado dos fatos ocorridos e das histórias das pessoas que por ali passaram e que ali vivem no presente. Sendo assim, interpretar uma paisagem, refletir sobre a ordem social e as configurações do lugar de vivencia, significa procurar desvelar e compreender a organização e transformação do espaço, além da própria experiência espacial dos sujeitos envolvidos.

O desenvolvimento desse "olhar espacial", desde os anos iniciais do ensino fundamental, apresenta-se essencial para a formação de pessoas capazes de entender os contextos sociais e políticos em que vivem e nos quais tomadas. E a partir desse entendimento crítico, dessa leitura de mundo, é que os sujeitos contemporâneos podem se posicionar e agir frente à realidade vivida e aos contextos mais amplos.

Assim, os professores que atuam na educação básica deveriam ser os responsáveis por contribuir para o desenvolvimento deste "olhar espacial". Entretanto, muitas vezes, esses professores não conhecem os conteúdos geográficos básicos e nem percebem como tais conteúdos estão enraizados na realidade dos alunos. Cavalcanti (2010. p. 1) aponta que uma das principais angústias desses professores é mostrar a importância dos conteúdos da Geografia para os alunos. Por insegurança, muitos educadores continuam demonstrando atitudes conservadoras em relação aos conteúdos. A autora ainda ressalta que, mais do que procurar por modelos acabados, vários educadores buscam entender a complexidade do ato de ensinar e a importância das "orientações teóricas seguras, conhecimento da realidade e dos processos da escola, convicção sobre os modos de atuação nessa instituição". Retomamos novamente a importância de o projeto pedagógico da escola ser construído de forma contextualizada com a realidade da comunidade, na qual o aluno se insere e com a participação de toda a equipe escolar.

Guimarães (2009, p. 304) afirma que o grande desafio dos professores de Geografia frente ao mundo em que vivemos é: 
compreender suas contradições, imposições, possibilidades e perversidades. O mundo da mobilidade, do tempo veloz, do encurtamento das distâncias e da intensa circulação de textos em diferentes suportes informacionais gera impasses e perplexidades aos docentes. A compreensão do novo cenário de abundância audiovisual e de profusão intensa de linguagens que envolvem, motivam, ensinam os estudantes, no atual período histórico, tem sido compreendida como um dos maiores desafios dos professores e das escolas.

Como expressa a autora, esse novo cenário educacional gera conflitos, impasses e se torna um desafio para os professores - e para as escolas -, principalmente para aqueles que ainda fundamentam as suas práticas numa abordagem tradicional. Nesse contexto, a Educação à Distância aparece como um exemplo claro do novo cenário, e cada dia mais vem se expandindo e se consolidando, sobretudo no que tange aos cursos destinados à formação dos professores. Podemos inferir então, que, os professores que muitas vezes ficam "perplexos" diante desse novo cenário, estão hoje vivendo uma formação na qual estão em contato com todo o aparato audiovisual e de novas linguagens, o que por si já representa oportunidades de acesso a tais recursos e de aprendizagem sobre como trabalhar de forma consciente e fundamentada, utilizando outros suportes e outras linguagens.

Sabemos que somente o uso de tecnologias não garante uma abordagem de educação que motive e instigue o aluno, mais importante do que isso é a postura e a prática pedagógicas do professor.

Tendo em vista o complexo cenário que se configura no século XXI, e o papel fundamental do ensino de Geografia, que é a análise do espaço geográfico em todos os níveis de ensino, especialmente nos anos iniciais - foco dessa reflexão -, surge a necessidade de se considerar as dicotomias existentes entre as diferentes abordagens, analisando-as de maneira crítica e, ao mesmo tempo, buscando caminhos alternativos. Vale ressaltar que os avanços tecnológicos e teóricos contribuem significativamente para a reconstrução das práticas do ensino de Geografia. Assim, os desafios postos aos docentes responsáveis por essa disciplina se direcionam no sentido de buscar discussões teóricas e metodológicas fundamentadas, considerando as propostas políticopedagógicas, bem como o papel político e social da Geografia escolar.

\section{A CONFIGURAÇÃo CURRICULAR do ENSINO DE GEOGRAFIA NOS CURSOS DE PEDAGOGIA À DISTÂNCIA}

À luz do referencial teórico explicitado anteriormente, buscamos verificar como o ensino de Geografia é proposto nos projetos pedagógicos dos cursos de Pedagogia à distância. A análise será realizada tendo como 
referência os seguintes pontos: análise das nomenclaturas e ementas das disciplinas voltadas ao ensino de Geografia; levantamento e análise das bibliografias sugeridas; e, por fim, a comparação das cargas. Por meio deste estudo analisamos alguns aspectos importantes em relação aos delineamentos do ensino de geografia nos cursos de Pedagogia à distância.

Em relação à carga-horária destinada às disciplinas voltadas para o ensino de Geografia nos projetos, podemos perceber, de acordo com o Gráfico 1 , que em $42 \%$ dos projetos a carga horária é dividida entre as disciplinas História e Geografia, ou seja, essas disciplinas ainda são trabalhadas de forma conjunta. Considerando que a separação dessas duas disciplinas ocorreu, nos anos iniciais de escolarização, na década de 1990, verificamos que a formação superior dos professores está em descompasso com a própria realidade da escola.

Gráfico 2 - Percentual de carga horária da disciplina destinada ao ensino de geografia nos cursos de pedagogia a distância.

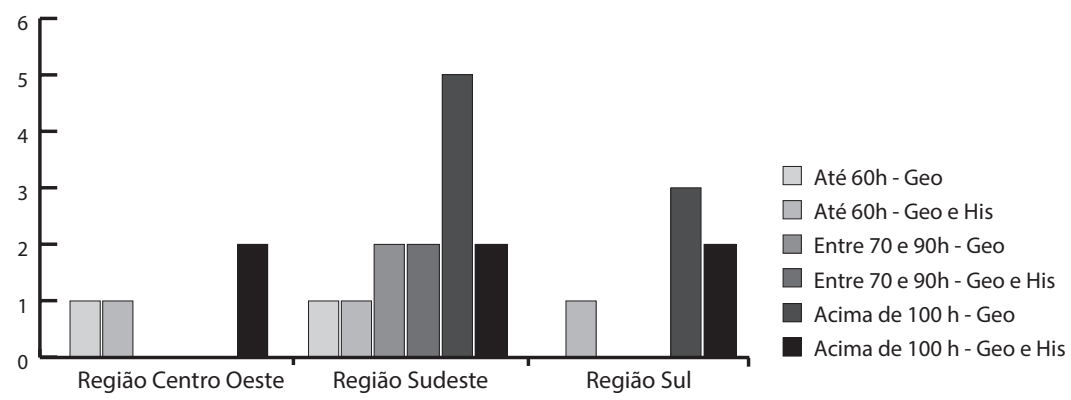

Fonte: ARAÚJO, 2013

A carga horária que mais se destaca para o ensino de Geografia é acima de 100 horas, e está presente em projetos de oito instituições. Tratamos este dado como importante, tendo em vista que as instituições já estão destinando um tempo considerável no projeto pedagógico de seus cursos ao desenvolvimento dos conhecimentos geográficos. No entanto, as outras instituições analisadas ainda mostram um quadro preocupante por causa da diversidade de cargas horárias em relação a esse conteúdo específico, como em três instituições que trabalham a Geografia e a História juntas, dividindoas em um total de 60 horas, o que resulta em uma carga horária mínima, de apenas 30 horas, destinadas ao ensino de Geografia.

No que diz respeito às nomenclaturas e ementas das disciplinas voltadas para o ensino de Geografia verificamos que os projetos apresentam 
uma grande diversidade de proposições para a disciplina voltada ao ensino de Geografia, tanto em relação às cargas horárias, como verificamos anteriormente, como em relação às nomenclaturas e conteúdos abordados.

Um primeiro aspecto verificado diz respeito à abordagem dada à disciplina, que ora é trabalhada junto com a História, ora é tratada separadamente. É possível verificar que, do total de vinte e um projetos analisados, nove deles agrupam as disciplinas de Geografia e História como sendo um único componente curricular. O quadro acima nos mostra também que em três projetos a Geografia e a História são tratadas como Ciências Sociais.

As discussões acerca da junção das disciplinas Geografia e História iniciaram-se na década de 1930 com Anísio Teixeira, mas foi somente na década de 1960 que as duas disciplinas começaram a ser trabalhadas conjuntamente. Autores como Novaes (2006) e Buitoni (2010) discutem sobre os prejuízos causados a essas duas disciplinas após a referida junção. Tal situação se agravou ainda mais com a inclusão, na década de 1970, da disciplina Educação Moral e Cívica (EMC), que passou a integrar a disciplina de Estudos Sociais, juntamente com a História e a Geografia. Verificamos que apesar de, na década de 1990, o ensino dessas duas disciplinas terem sido separados novamente, ainda há fortes resquícios desse modelo de junção nos currículos dos cursos de Pedagogia analisados. Em $42 \%$ dos projetos tal realidade ocorre. Cabe-nos questionar se o prejuízo demonstrado na década de 1960 e 1970 com a junção dos conteúdos de Geografia e História se configura nesses projetos e na realidade do ensino dessas disciplinas, e, por conseguinte, na formação dos professores.

Como exemplo, destacamos as ementas de duas disciplinas destinadas ao ensino de Geografia da instituição "K". Nessa instituição, as disciplinas História e Geografia são ministradas juntas, História e Geografia I e História e Geografia II, em 30 horas para cada disciplina.

Abaixo consta a ementa da disciplina História e Geografia I:

História e Geografia I: O estatuto do saber histórico. (Des)velando a história. Natureza da ciência História. Uma História plural. Identificação de objetos, sujeitos, fontes e tempos históricos. A escrita da História. Principais correntes historiográficas. Itinerários do saber histórico escolar. A disciplina História: articulando os saberes. Principais características da História como disciplina escolar. Trajetórias da História como disciplina escolar no Brasil. Propostas curriculares para o ensino da História. Os PCN de História e as diretrizes curriculares para a Educação Infantil e o Ensino Fundamental. A Geografia como ciência e como disciplina escolar. Percepção e diagnóstico da Geografia vivenciada. Os significados e as representações sobre a Geografia, construídos 
no contato com a Geografia vivenciada na escola como discente e docente. A Geografia como ciência: principais momentos da construção do pensamento geográfico. Características individualizadoras da tradição didática da Geografia escolar. Principais características da Geografia como disciplina escolar e os pontos de convergência e ruptura entre essa e a Geografia como disciplina acadêmica. Os conceitos e os documentos estruturadores da Geografia como disciplina escolar. Caracterização do espaço geográfico como objeto de estudo da Geografia. Conceito de lugar e sua importância auxiliar no estudo da realidade do mundo em que vivemos. Os conceitos estruturadores da interpretação geográfica. Conceitos geográficos de paisagem e território na análise de imagens e de situações da realidade espacial. Geografia como conteúdo escolar: PCNs e programas de referência. Documentos institucionalizadores da Geografia escolar e suas características básicas.

Como podemos verificar, há uma grande quantidade de conteúdos para serem desenvolvidos em trinta horas. Em relação a esse ponto, esclarecemos que nem as disciplinas com mais de 100 horas apresentam em suas ementas essa quantidade de temas propostos. Consideramos que, apesar de parecer uma ementa que aborda conteúdos importantes da Geografia, pode ser inviável o desenvolvimento dessa quantidade de conteúdos nas condições propostas, ou seja, a carga horária destinada aos conteúdos apresenta-se baixa. É razoável levantarmos a suspeita de que os conteúdos são desenvolvidos de forma superficial, o que não contribui efetivamente para a formação dos futuros professores. Sendo assim, verificamos que em alguns casos, dependendo da carga horária despendida, pode haver prejuízos nos conteúdos destas disciplinas.

Para complementar os dados acima levantados, realizamos a contagem de conteúdos que são propostos nas ementas, visando descobrir a forma com que essas ementas são construídas, conforme mostra o gráfico a seguir:

Gráfico 3 - Percentual de temas abordados nas ementas
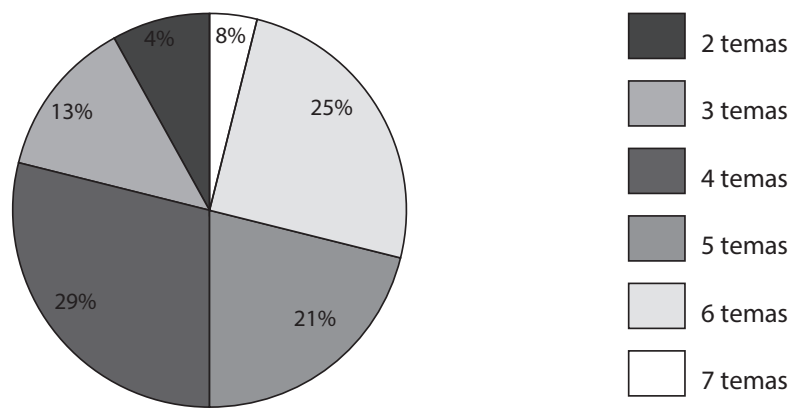

Fonte: ARAÚJO, 2013. 
Verificamos que $50 \%$ das ementas são construídas propondo quatro ou cinco temas diferentes para serem desenvolvidos. Também identificamos ementas que utilizam somente dois temas, e outras que propõem até sete temas diferentes, o que confirma novamente a grande diversidade nas propostas das ementas.

Abaixo destacamos a ementa que propõe o desenvolvimento de sete temas diferentes:

Instituição "L": Ensino e Aprendizagem de Geografia I: A Geografia como ciência. Compreensão do espaço produzido pela sociedade (espaço relacional). Aspectos teórico-metodológicos do ensino da Geografia. Objetivos e finalidades do Ensino da Geografia na Proposta Curricular do Curso de Pedagogia. A formação do conceito de espaço pela criança. $O$ estudo do meio, partindo do local da vivência da criança. $O$ uso de recursos didáticos para o ensino: gráficos, tabelas, representações cartográficas. Aplicação prática dos conhecimentos teórico-metodológicos. Análise crítica da bibliografia existente na área de Geografia. Ensino e Aprendizagem de Geografia I Recursos e instrumentos de avaliação da aprendizagem na Geografia no ensino fundamental.

Ensino e Aprendizagem de Geografia II: A prática docente como eixo fundamental na formação inicial do educador sob fundamento da articulação teoria e prática no contexto da escola básica. Discutir as dimensões éticas, sociopolítica, humana, técnica e os princípios epistemológicos do ensino de Geografia. Elaborar e executar planejamento de atividades de ensino de Geografia em unidades escolares de Ensino Fundamental sob orientação. Os Parâmetros curriculares Nacionais e o ensino de Geografia no ensino fundamental.

Conforme podemos observar, o ensino de Geografia no curso de Pedagogia da Instituição "L" é desenvolvido em duas disciplinas, cada uma com 60 horas-aula, totalizando 120 horas. Na ementa propõe-se que a disciplina seja iniciada enfocando a Geografia como ciência e mostrando certa interligação dos temas propostos. Propõe-se também a aplicação prática dos conhecimentos teórico-metodológicos, observada somente em mais uma ementa das 21 analisadas. Podemos observar que, como nas demais disciplinas, os temas mais recorrentes referem-se ao pedagógico, não tendo muito enfoque os conteúdos básicos dessa disciplina. Fonseca (2010) afirma que, geralmente, os cursos de Pedagogia vêm seguindo uma cultura acadêmica de valorização dos saberes pedagógicos e de não valorização dos conhecimentos básicos das disciplinas, também importantes para os professores que trabalham com educação infantil e anos iniciais. 
Há instituições que apresentam apenas dois temas em suas propostas e, reafirmando a proposição acima, esses temas também focam o pedagógico:

Instituição "H": Fundamentos teóricos do ensino de história e geografia, currículo, metodologia, recursos e avaliação.

Instituição " $M$ ": O ensino de Geografia na educação básica: pressupostos teórico-metodológicos, relação método-conteúdo, avaliação.

Dessas duas ementas, a primeira apresenta uma proposta que será desenvolvida em 60 horas e a segunda, uma proposta para 120 horas. Por meio da análise da segunda ementa, verificamos que para uma disciplina que será desenvolvida em 120 horas, a quantidade de temas abordados não condiz com a carga horária, ou podemos supor que essa ementa segue o modelo geral e superficial com que as ementas vêm sendo construídas, conforme nos mostram os resultados das pesquisas empreendidas por Libâneo (2010) e Gatti \& Barreto (2009).

Na pesquisa desenvolvida por Arruda (2011, p. 107), intitulada "Dimensões da aula e das práticas pedagógicas na Educação Superior Presencial e a Distância", os depoimentos dos professores pesquisados revelam que"a ementa da disciplina é seguida de forma mais precisa na $\mathrm{EaD}$, devido, em parte, ao controle realizado por meio dos registros dos materiais e aulas dos professores".

Outro aspecto apresentado pela autora é que pelo fato de a modalidade à distância ser desenvolvida em tempos e espaços diferentes, o planejamento sofre menos alterações. Arruda (2011) enfatiza a importância de haver planejamento tanto nos cursos presenciais quanto nos à distância. Reforçamos essa importância e acrescentamos que a preocupação sobre a organização de um curso e de uma disciplina e a reflexão sobre esses aspectos devem estar presentes desde a construção do projeto pedagógico e da proposição das ementas das disciplinas. Tal fato se evidencia ainda mais nos cursos à distância, pois o material didático produzido tem como referência os projetos pedagógicos e as ementas das disciplinas.

Por meio das análises realizadas, consideramos que várias das ementas, da forma como foram produzidas, não se mostram como um caminho claro e profícuo para que os professores que irão ministrar tal disciplina possam organizar, da melhor forma possível, a sua prática pedagógica.

Em uma análise realizada acerca das ementas das disciplinas voltadas para o ensino de Geografia, em projetos de cursos de Pedagogia, Libâneo 
(2010, p. 571) concluiu que"a maioria das ementas segue o modelo descritivo e genérico, com raras menções aos temas e procedimentos investigativos próprios dessas disciplinas". Reiteramos a conclusão do autor quanto ao aspecto genérico das ementas e à falta dos procedimentos investigativos da Geografia e ainda enfatizamos que a questão pedagógica se sobressai em detrimento dos conteúdos próprios da Geografia.

Outra análise que julgamos pertinente refere-se aos referenciais teóricos utilizados. Dos vinte e um projetos e fichas de disciplinas analisadas, em dezesseis deles há a listagem das bibliografias para os cursos. Analisando cada instituição, identificamos referências bibliográficas que se repetem. Apesar de em algumas instituições existirem duas disciplinas voltadas para o ensino de Geografia, foram consideradas as bibliografias por instituição.

No quadro abaixo apresentamos as bibliografias com as respectivas quantidades de instituições que as apresentam em suas bibliografias básicas e complementares:

Quadro 1 - Referências bibliográficas apresentadas em mais de um projeto

\begin{tabular}{|l|c|}
\hline $\begin{array}{l}\text { Referência bibliográficas que se repetem } \\
\text { nas bibliografias básicas e complementares }\end{array}$ & $\begin{array}{c}\text { Número de } \\
\text { vezes que } \\
\text { aparecem }\end{array}$ \\
\hline $\begin{array}{l}\text { ALMEIDA, R. S.; PASSINE, E. Y. Espaço Geográfico: ensino e representação. São Paulo: } \\
\text { Contexto, 1994. }\end{array}$ & 10 \\
\hline $\begin{array}{l}\text { BRASIL. Parâmetros Curriculares Nacionais: Geografia. Ministério da Educação e do } \\
\text { Desporto: Secretaria de Educação Fundamental. Brasília, 1997. }\end{array}$ & 8 \\
\hline $\begin{array}{l}\text { PENTEADO, Heloisa Dupas. Metodologia do ensino de História e Geografia. São Paulo, } \\
\text { Cortez, 1992. }\end{array}$ & 6 \\
\hline MORAES, A. C. R. Geografia: pequena história escrita. 8. ed. São Paulo: Hucitec, 1988. & 5 \\
\hline $\begin{array}{l}\text { SANTOS, Milton. A natureza do espaço: técnica e tempo, razão e emoção. São Paulo: } \\
\text { Edusp, 2002. }\end{array}$ & 5 \\
\hline $\begin{array}{l}\text { SIMIELLI, Maria Elena. Primeiros Mapas: como entender e construir. São Paulo: Ática, } \\
\text { 1993. Volumes: 1, 2, 3, 4. }\end{array}$ & 5 \\
\hline CARLOS, A. F. A. (Org.). A Geografia na sala de aula. São Paulo: Contexto, 2002. & 3 \\
\hline $\begin{array}{l}\text { CASTELLAR, Sonia. Educação geográfica: teorias e práticas docentes. } \\
\text { São Paulo: Contexto, 2006. }\end{array}$ & 3 \\
\hline $\begin{array}{l}\text { CASTRO, Inas Elias de; CORREA, Roberto; GOMES, Paulo Cesar da Costa. Geografia: conceitos } \\
\text { e temas. 8. ed. Rio de Janeiro: Bertrand, 2006. }\end{array}$ & 3 \\
\hline $\begin{array}{l}\text { CASTROGIOVANNI, C. C.; CALLAl, H. C.;SCHAFFER, N. O. \& KAERCHER, N. A. Geografia em sala } \\
\text { de aula: práticas e reflexões. 2. ed. Porto Alegre: Editora da Universidade/UFRS/Associação } \\
\text { dos Geógrafos Brasileiros - Seção Porto Alegre, 1999. }\end{array}$ & 3 \\
\hline $\begin{array}{l}\text { LACOSTE, Y. A Geografia - isso serve, em primeiro lugar para fazer a guerra. Campinas, } \\
\text { SP: Papirus, 1998. }\end{array}$ & 3 \\
\hline $\begin{array}{l}\text { PONTUSCHKA, N. N. OLIVEIRA, A. U. Geografia em Perspectiva: ensino e pesquisa. São } \\
\text { Paulo: Contexto, 2002. }\end{array}$ & 3 \\
\hline
\end{tabular}




\begin{tabular}{|l|c|}
\hline $\begin{array}{l}\text { Referência bibliográficas que se repetem } \\
\text { nas bibliografias básicas e complementares }\end{array}$ & $\begin{array}{c}\text { Número de } \\
\text { vezes que } \\
\text { aparecem }\end{array}$ \\
\hline $\begin{array}{l}\text { CALLAI, Helena Copetti. Os estudos sociais nas séries iniciais. In: O Ensino de Estudos } \\
\text { Sociais. 2. ed. Ijuí: Unijuí, 2002. }\end{array}$ & 2 \\
\hline $\begin{array}{l}\text { CASTROGIOVANNI, A. Ensino de Geografia: práticas e textualizações no cotidiano. Porto } \\
\text { Alegre: Mediação, 2000. }\end{array}$ & 2 \\
\hline LEME, D. M. P.C.; et al. O Ensino de Estudos Sociais no primeiro grau. São Paulo: Atual, 1997. & 2 \\
\hline NILDECOFF, Maria Teresa. A escola e a compreensão da realidade. São Paulo: Brasiliense, 1979. & 2 \\
\hline $\begin{array}{l}\text { PONTUSCHKA, Nídia Nacib; et al. Para Ensinar a Aprender Geografia. 3. ed. São Paulo: } \\
\text { Cortez, 2009. }\end{array}$ & 2 \\
\hline $\begin{array}{l}\text { SANTOS, M. Técnica, espaço, tempo: globalização e meio técnico-científico informacio- } \\
\text { nal. São Paulo: Hucitec, 1998. }\end{array}$ & 2 \\
\hline
\end{tabular}

Fonte: ARAÚJO, 2013.

Podemos observar que os Parâmetros Curriculares Nacionais para o Ensino de Geografia, apesar de serem citados apenas em quatro ementas, é a segunda referência bibliográfica mais sugerida. Tal fato nos mostra que, apesar de constarem como tema na minoria das ementas, esses documentos continuam sendo norteadores para o ensino de Geografia. A terceira referência mais utilizada é uma produção que trata das metodologias de História e Geografia juntas, o que pode representar a tendência de várias das instituições pesquisadas em agrupar tais disciplinas.

Há autores que se destacam nas bibliografias com diferentes produções, dentre os quais Milton Santos, um autor de referência do pensamento geográfico contemporâneo no Brasil. Esse geógrafo delineava em seus textos uma perspectiva crítica da Geografia, dando destaque para a constituição do que chamou de meio técnico-científico e informacional. Haesbaert \& Gonçalves $(2011$, p. 17) ressaltam como principais características desse autor: a intuição sensível, a argumentação e o "refinamento teórico", e apresentam como um dos maiores legados de Milton Santos "[o] repensar criticamente a organização do território". Consideramos salutar a utilização de intelectuais como Milton Santos na preparação dos professores que atuarão no ensino de Geografia, pois esse autor trata de questões teóricas e conceituais do campo de conhecimento da Geografia em uma vertente crítica.

A bibliografia que mais se destacou nos projetos analisados foi o livro "Espaço Geográfico: ensino e representação", de Rosângela Doin de Almeida e Elza Yasuko Passini. Essa obra evidencia a importância de se trabalhar o espaço, sua percepção e representação nos anos iniciais de escolarização. Para isso, é proposta a elaboração dos conceitos espaciais por meio da interação com o meio, 
a importância do aprendizado espacial no contexto sociocultural, em busca do desenvolvimento de uma visão crítica do espaço social, além de evidenciar a importância da educação cartográfica. De acordo com Almeida \& Passini (1989):

O desenvolvimento da noção de espaço e sua representação não surge em função das tarefas dadas em sala de aula. Procuramos mostrar que o professor pode de maneira indireta estimular o estabelecimento de todos os tipos de relações espaciais entre os objetos em diversos momentos. É através da ação em seu espaço cotidiano e da reflexão sobre ela que a criança terá oportunidade de chegar à abstração reflexiva ou à concepção do espaço e sua organização (ALMEIDA \& PASSINI, 1989, p. 90).

As autoras também descrevem exemplos de atividades que podem ser realizadas com os alunos, na tentativa de propiciar a ação em seu espaço e reflexão sobre essa ação. Apesar de não ser muito recente, consideramos que se trata de uma obra importante para o ensino de Geografia, tendo em vista a pertinência das reflexões que são realizadas ao longo do texto e os exemplos de atividades que são apresentados. Salientamos que as autoras desse livro já produziram outros textos mais atuais, no entanto, essas últimas obras não constam nos projetos.

Constatamos que $61 \%$ das bibliografias sugeridas são obras com mais de dez anos de produção, ou seja, foram publicadas antes de 2002. A bibliografia mais atual (sugerida em mais de uma instituição) é de 2009, e é citada em dois projetos, o que demonstra que não está havendo a busca de atualização dos referenciais teóricos da disciplina voltados ao ensino de Geografia nos cursos de Pedagogia à distância.

Reconhecemos a importância dos referenciais clássicos para as disciplinas, no entanto, salientamos a importância da inserção de referenciais produzidos mais recentemente, que podem propor discussões mais próximas da realidade atual dos alunos.

O estudo realizado nos permite tecer algumas conclusões acerca dos delineamentos das propostas curriculares para o ensino de Geografia nos cursos de Pedagogia à distância, objeto de nosso estudo. Verificamos uma grande discrepância entre as propostas de cada instituição e levantamos alguns pontos que merecem atenção:

- em relação às cargas horárias, a grande maioria das instituições destina uma carga horária de 11 a 20\% às disciplinas específicas. O ensino de Geografia é proposto em $100 \%$ dos projetos, e em sua maioria é planejado com uma carga horária superior a 100 horas. Geralmente, a carga horária de Geografia é a mesma destinada ao ensino de História; 
- a organização das ementas, em sua maioria, é superficial e genérica e apresenta temas amplos, que não priorizam os aspectos investigativos da Geografia;

- a metade das ementas propõe o desenvolvimento de 4 ou 5 temas diferentes. No entanto, essa quantidade de temas não é condizente com as cargas horárias destinadas aos mesmos, porque ora as ementas apresentam muitos temas para poucas horas, ora apresentam o contrário;

- as questões metodológicas e pedagógicas do ensino de Geografia se destacam como sendo a temática mais abordada nas ementas;

- os Parâmetros Curriculares Nacionais, apesar de serem apresentados como tema em somente quatro ementas, são apresentados como o segundo referencial teórico mais utilizado nas ementas, o que mostra que tais documentos são considerados diretrizes do ensino de Geografia nos cursos de Pedagogia;

- observamos uma grande diversidade de bibliografias propostas, a maioria das obras, no entanto, datadas com há mais de 10 anos de produção.

Deacordo com esses apontamentos, consideramos que o delineamento curricular da disciplina Geografia no processo de formação dos professores na modalidade a distância está longe de expressar consenso, ou uma perspectiva similar, nas universidades investigadas. Ao contrário, as diferenciações e discrepâncias nas propostas são perceptíveis e cada instituição define o seu projeto pedagógico de acordo com suas concepções de ensino e aprendizagem e de formação de professores, bem como a partir do jogo de poder que se instala no processo de construção das propostas pedagógicas.

Dada a dinamicidade do panorama dos cursos superiores de educação à distância, do momento em que os dados foram coletados, até a data de conclusão do presente trabalho, acreditamos que novos cursos de Pedagogia estejam sendo encaminhados e ofertados. Esperamos que os dados levantados nesta pesquisa contribuam no sentido de direcionar a produção desses projetos pedagógicos e o processo de construção e proposição da disciplina Geografia nos cursos de Pedagogia na modalidade à distância. 


\section{TEACHING GEOGRAPHY IN DISTANCE-LEARNING PEDAGOGY COURSES}

ABSTRACT: This paper presents an analysis of the proposed curriculum for the teaching of Geography in the pedagogical projects of distant-learning pedagogy courses in public higher education institutes in the Midwest, South and Southeast of the country. It seeks to identify the outlines of Geography teaching in such courses. The paper addresses theoretical and methodological perspectives for the teaching of Geography and presents the findings. In the studied universities, there is no consensus or similar perspective on curriculum outline for the teaching of Geography, regarding the process of teachers training in distance-learning modality.

KEYWORDS: Teaching Geography. Distance Education. Pedagogy.

\section{LA ENSEÑANZA DE GEOGRAFÍA EN CURSOS DE PEDAGOGÍA A DISTANCIA}

RESUMEN: Este artículo presenta un análisis acerca de las propuestas curriculares de las asignaturas orientadas a la enseñanza de Geografía en los proyectos pedagógicos de los cursos de Pedagogía bajo la modalidad a distancia de las instituciones públicas de enseñanza superior en las regiones del Medio Oeste, Sur y Sureste del país, buscando identificar los lineamientos de la enseñanza de Geografía en los cursos mencionados. El texto abarca las perspectivas teóricas y metodológicas de la enseñanza de Geografía y presenta sus resultados. Se considera que las directrices curriculares de la disciplina de Geografía en el proceso de formación de los profesores bajo la modalidad a distancia está lejos de expresar un consenso o una perspectiva similar en las universidades investigadas.

Palabras claves: Enseñanza de Geografía. Educación a Distancia. Pedagogía.

\section{REFERÊNCIAS}

ALMEIDA, R. D.; PASSINI, E. Y. O Espaço Geográfico: ensino e representação. São Paulo: Contexto, 1989.

ARAÚJO, S. M. O lugar do ensino de geografia nos cursos de pedagogia na modalidade à distância: possibilidades e desafios. Dissertação (Mestrado em Educação) - Programa de Pós-Graduação em Educação, Universidade Federal de Uberlândia - UFU, 2013.

BUITONI, M. M. S. (Coord.) Geografia: ensino fundamental. Brasília: Ministério da Educação, Secretaria de Educação Básica, 2010. (Coleção Explorando o Ensino; v. 22)

CALLAI, H. C. Aprendendo a ler o mundo: a geografia nos anos iniciais do ensino fundamental. In: Caderno CEDES, v. 25, n. 66. Campinas, maio-ago. 2005. 
CAVALCANTI, L. S. Geografia e Práticas de Ensino. Goiânia: Alternativa, 2002.

. A geografia e a realidade escolar contemporânea: avanços, caminhos, alternativas. In: Anais do I Seminário Nacional: currículo em movimento - Perspectivas Atuais. Belo Horizonte, nov. 2010.

Ensinar Geografia para autonomia do pensamento: o desafio de superar dualismos pelo pensamento teórico crítico. In: Revista da ANPEGE. v. 7, n. 1, número especial, p. 193-203, out. 2011.

FONSECA, S. G. O trabalho do professor na sala de aula: relações entre sujeitos, saberes e práticas. In: Revista Brasileira de Estudos Pedagógicos, Brasília, v. 91, n. 228, p. 390-407, maio-ago., 2010.

GATTI, B. A.; BARRETO, E. S. S. Professores do Brasil: impasses e desafios. Brasília: UNESCO, 2009.

GUIMARÃES, I.V. Possibilidades Criativas no Ensino de Geografia: diferentes registros e linguagens na sala de aula. In: FONSECA, Selva Guimarães (Org.). Ensino Fundamental: conteúdos, metodologias e práticas. Campinas, SP: Editora Alínea, 2009.

; SANTOS, K. A.; MACHADO, L. M. D. Crianças e práticas espaciais no mundo globalizado. In: Ensino em Re-vista. v. 19, n. 2, jul-dez. 2012.

HAESBAERT, R.; GONÇALVES, C. W. P. Dez anos sem Milton Santos. In: Revista GEOgraghia, v. 13, n. 25, 2011. Disponível em: <www.uff.br/geographia/ojs/index.php/ geographia/article/view/402>. Acesso em: 20 nov. 2012.

LIBÂNEO, J. C. O ensino da Didática, das metodologias específicas e dos conteúdos específicos do ensino fundamental nos currículos dos cursos de Pedagogia. In: Revista Brasileira de Estudos Pedagógicos. Brasília, v. 91, n. 229, p. 562-583, set.-dez. 2010.

PONTUSCHKA, N. N.; PAGANELLI, T. I.; CACETE, N. H. Para Ensinar e Aprender Geografia. 3. ed., São Paulo: Cortez, 2009.

\footnotetext{
Sarah Mendonça de Araúuo é graduada em Pedagogia pelo Centro Universitário Luterano de Palmas, pós-graduada em Supervisão Escolar pela Faculdade Católica de Uberlândia, e mestre em Educação pela Universidade Federal de Uberlândia. Atualmente, ocupa o cargo de Técnica em Assuntos Educacionais da Universidade Federal de Uberlândia, e atua como assessora da Diretoria de Educação à Distância. Tem experiência na área de educação, com ênfase em Tecnologias Educacionais, Educação à Distância e Supervisão Escolar.

E-mail:sarahmend@hotmail.com
} 
IARA Vieira Guimarães é professora da Faculdade de Educação da Universidade Federal de Uberlândia e do Programa de Pós-Graduação em Educação (Linha de Pesquisa Saberes e Praticas Educativas - FACED/UFU). Possui graduação em Geografia pela Universidade Federal de Uberlândia (1992), mestrado em Geografia Humana pela Universidade de São Paulo (1998), e doutorado em Educação pela Universidade de São Paulo (2006). É membro do Grupo de Pesquisa Formação Docente, Saberes e Práticas de Ensino de História e Geografia. Possui experiência nas áreas de Educação e Geografia, com ênfase em ensino e aprendizagem de Geografia, metodologias e práticas pedagógicas, e formação de professores.

E-mail: iarasuimaraes@faced.ufu.br 